\title{
Comparing the Efficacy of Hyaluronic Acid and Platelet Rich Plasma Treatment by using Visual analogue Scale in the Patients of Knee Osteoarthritis
}

\section{Muhammad Ali, ${ }^{1}$ M. Mudassar Azam, ${ }^{2}$ Maimoona Zaheer, ${ }^{3}$ Fahad Wali Shah Khagha, ${ }^{4}$ Amjad Waseem Shah, ${ }^{5}$ Faisal Masood ${ }^{6}$}

\begin{abstract}
Objective: To compare the efficacy of Hyaluronic acid (HA) and Platelet rich plasma (PRP) for treatment of Knee osteoarthritis.

Methods: A randomized controlled trial done at department of Orthopedics Unit-I, Mayo Hospital Lahore. 130 cases fulfilling inclusion criteria were enrolled. All patients were divided into two groups. In group-A, cases were treated with HA (1\% sodium Hyaluronate mixed in a phosphate buffered saline). In group-B, cases were treated with $10 \mathrm{ml}$ of PRP extracted from $100 \mathrm{ml}$ of their blood. Before and after procedure pain and efficacy was recorded.

Results: The frequency of pain reduction $\geq 50 \%$ was statistically higher in PRP group as compared to HA group, $\mathrm{p}$-value $<0.05$.

Conclusion: Through the findings of this study we conclude that the efficacy of efficacy of PRP was high than HA for treatment of Knee osteoarthritis.

Key Words: Osteoarthritis, platelet-rich plasma, efficacy, hyaluronic acid.

How to Cite: Ali M, Azam M.M, Zaheer M, Shah F, Shah A, Masood F. Comparing the efficacy of hyaluronic acid and platelet rich plasma treatment by using visual analogue scale in the patients of knee osteoarthritis. Esculapio.2020;16(04):37-40.
\end{abstract}

DOI: https://doi.org/10.51273/esc20.251648

\section{Introduction}

A rthritis is of the most prevalent chronic conditions in cases with advanced age. The most commonest joint to be effected is the knee joint with a prevalence up to $41 \%$, compared to the prevalence of $30 \%$ in hands and $19 \%$ in hips. ${ }^{1}$ Kellgren-Lawrence $(\mathrm{K} / \mathrm{L})$ along with $\mathrm{x}$-rays is utilized to diagnose and grade the severity of disease. Its overall score ranges from $0-4$ with confirmed diagnosis of knee osteoarthritis at Grade 2., ${ }^{2,3}$ There is an

1. Muhammad Ali

3. Maimoona Zaheer

5. Amjad Waseem Shah

2. M. Mudassar Azam

4. Fahad Wali Shah Khagha

6. Faisal Masood

1,4-6. Department of Orthopaedic Surgery, King Edward Medical University, Lahore

2. Department of Basic Health Unit, King Edward Medical University, Lahore

3. Demonstrator, Department of Physiology, King Edward Medical University, Lahore

4. Department of Orthopaedic Surgery, King Edward Medical University, Lahore

\section{Correspondence:}

Dr. Muhammad Ali, Department of Orthopaedic Surgery, King Edward Medical University, Lahore

E-mail.: alibhidwal7272@gmail.com

Submission Date:

1st Revision Date:

Acceptance Date:
$15-10-2020$

$15-11-2020$

25-11-2020 evidence of repairing cartilage by stimulation method and there are many other methods to reduce cartilage damage that is by inhibiting catabolic enzymes or supressing genes, use of growth factors or by artificial replacement of cartilage. ${ }^{4}$ PRP injections is a platelet concentration above base line have a great acceptance in orthopaedics. ${ }^{5-7}$

According to a recent systematic review, short and long duration follow ups have shown that the treatment guidelines of injecting PRP inside the knee synovial cavity, is found to be more efficacious then only injecting injections of saline Hyaluronic acid, placebos, ozone and steroids. ${ }^{8-10}$ Many physician do agree that by incorporating HA (viscosupplementation) into synovial cavity, it magically restore the physiological viscoelastic qualities of pathological synovial fluid. ${ }^{11,12}$ Platelet contains growth factors: platelet-derived growth factors ( $a, b)$, transforming growth factor (TGF)- $\beta$, vascular endothelial growth factor, epidermal growth factor, fibroblast growth factor. ${ }^{5,12}$

A team of scientist have found that the severity of visual analogue score of 15 subjects (55.5\%) falls to 
the half of their previous score at their third month of treatment with PRP and 8 patients who were treated with HA, also showed a significant decrease in VAS with $p$-value $=0.227 .^{4}$

The rationale of this study is to compare HA and PRP for treatment of knee osteoarthritis in our local patients. We found no local study and global study reported high rate of reduction $(<50 \%)$ in pain from baseline but on comparing with HA the difference was insignificant. On the basis of findings of this study we want to see its role in our local population so that in future PRP can be utilized to gain quick recovery of the cases if found to be more effective.

It was a randomized controlled trial comprising 130 patients selected though non-probability consecutive sampling. 65 cases in each group were taken using percentage of $<50 \%$ decrease in VAS at 3 months. We used $80 \%$ power of study and $95 \%$ confidence level. Cases of age 30- 80 years of either gender with diagnosis of knee osteoarthritis (duration of symptoms more than 2 weeks) were included. Subjects having $\mathrm{Hb}<11 \mathrm{mg} / \mathrm{dL}$, history of previous knee surgery (on clinical record), blood disorders like hemophilia, etc, Systemic disorders (diabetes mellitus; BSR >120), Rheumatoid arthritis (on clinical signs and symptoms and digital $\mathrm{X}$-rays (stage III \& IV) $\}$, history of severe cardiovascular diseases, infections, history of immunosuppressive drugs, patients receiving anticoagulants, use of non-steroidal antiinflammatory drugs in the last 5 days before blood donation, were excluded. All patients were divided into 2 equal groups. In group-A, cases were treated with HA in which a very clear solution of sterile $1 \%$ sodium Hyaluronate in a phosphate buffered saline. In group-B, a total of $100 \mathrm{~mL}$ of blood through venous was taken and PRP was extracted in a $10-\mathrm{mL}$ syringe. Patients were called again after the duration of 3 months. Before and after procedure, pain and efficacy was recorded. All related information was recorded on attached proforma.

All collected data was entered and analysed using SPSS version 22. Categorical data like gender and $<50 \%$ reduction in pain was presented in form of Frequency (\%). Quantitative data (age, duration of pain, pain before and after 4 months) was presented as mean \pm S.D. Chi-square test was applied to compare efficacy of procedure in both groups. P-value $\leq 0.05$ was considered as significant.

\section{Results}

The mean age of cases in PRP and HA group was $48.26 \pm 13.32$ and $46.71 \pm 11.09$ years respectively, there were $84(64.6 \%)$ male and $46(35.4 \%)$ female cases in whole sample, moreover there were 53(81.5 $\%$ ) male and 12(18.5\%) female in PRP group while in HA group there were $31(47.7 \%)$ male and 34(52.3\%) female cases respectively. The mean duration of disease in PRP group was $10.74 \pm 4.59$ weeks and in HA group was $10.75 \pm 4.93$ weeks. In PRP group $\geq$ $50 \%$ reduction in pain was seen in $38(58.5 \%)$ cases and $<50 \%$ reduction seen in $27(41.5 \%)$ cases whereas in other group $\geq 50 \%$ reduction seen in $19(29.2 \%)$ cases and $<50 \%$ in $46(70.8 \%)$ cases. The frequency of pain reduction $\geq 50 \%$ was statistically higher in PRP group as compared to HA group, p-value $<0.05$. Results of all demographic features (age, gender and

Table 1: Descriptive Statistics of pain at baseline and at $3 r d$ months after treatment in both groups.

\begin{tabular}{lccccc}
\hline & Study groups & Mean & S.D & Min. & Max. \\
\hline Pain before & PRP $(\mathrm{n}=65)$ & 5.97 & 1.86 & 4 & 10 \\
& HA $(\mathrm{n}=65)$ & 7.57 & 2.07 & 4 & 10 \\
& Total $(\mathrm{n}=130)$ & 6.77 & 2.12 & 4 & 10 \\
Pain after 3 & PRP $(\mathrm{n}=65)$ & 3.32 & 1.52 & 2 & 6 \\
months & HA $(\mathrm{n}=65)$ & 4.71 & 1.75 & 2 & 7 \\
& Total $(\mathrm{n}=130)$ & 4.02 & 1.77 & 2 & 7 \\
\hline
\end{tabular}

Table 2: : Comparison of efficacy of treatments in both groups with respect to duration (weeks) and VAS.

\begin{tabular}{|c|c|c|c|c|c|c|}
\hline & \multirow{2}{*}{$\begin{array}{l}\text { Effi- } \\
\text { cacy }\end{array}$} & \multicolumn{2}{|c|}{ Study Groups } & \multirow{2}{*}{$\begin{array}{l}\text { Chi- } \\
\text { square }\end{array}$} & \multirow{2}{*}{$\begin{array}{c}\text { p- } \\
\text { value }\end{array}$} \\
\hline & & & PRP & HA & & \\
\hline \multirow{4}{*}{ 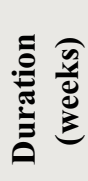 } & \multirow{2}{*}{$\begin{array}{l}<12 \\
\text { weeks }\end{array}$} & Yes & $22(59.5 \%)$ & $10(29.4 \%)$ & 6.462 & 0.011 \\
\hline & & No & $15(40.5 \%)$ & $24(70.6 \%)$ & & \\
\hline & \multirow{2}{*}{$\begin{array}{l}12 \text { weeks } \\
\text { or more }\end{array}$} & Yes & $16(57.1 \%)$ & $9(29.0 \%)$ & & \\
\hline & & No & $12(42.9 \%)$ & $22(71.0 \%)$ & 4.761 & 0.029 \\
\hline \multirow{4}{*}{ : } & \multirow[t]{3}{*}{$4-6$} & Yes & $28(66.7 \%)$ & $15(57.7 \%)$ & 0.556 & 0.456 \\
\hline & & No & $14(33.3 \%)$ & $11(42.3 \%)$ & & \\
\hline & & Yes & $10(43.5 \%)$ & $4(10.3 \%)$ & & \\
\hline & $7-10$ & No & $13(56.5 \%)$ & $35(89.7 \%)$ & 9.134 & 0.003 \\
\hline
\end{tabular}

obesity) showed that efficacy of PRP was higher than HA with p-value $<0.05$.

\section{Discussion}

Any joint of the body is susceptible to OA but the most common joints on the hit list of this disease are Knee, hip, spine, hand and foot. In 2011, the prevalence of osteoarthritis was $28 \%$ in Pakistani population. ${ }^{13}$ A study complied few studies on $(739$ patients, 817 knees, 39\% males, mean age of 59.9 years, with 38 weeks average follow-up) were 
analyzed. ${ }^{14}$ We in current study found that $84(64.6 \%)$ male and 46 (35.4\%). Kohsiban and his fellow colleague conducted a study and found out that all those subjects who were treated with PRP showed more pain improvement that the subject who were injected with HA. ${ }^{15}$ Meheux and his fellows did a systemic review in year 2015 and concluded that management of knee OA disease with PRP injection is far better than HA. Our research study had the results in line with the results of above mentioned worldwide studies. ${ }^{14}$ Mendia et al. did a research study on patients of knee OA and findings favoured the treatment with PRP rather than with any placebo or steroids. Similar results were drawn out from a systemic review of sixteen studies done by Chang et al. ${ }^{16,17}$ Kon E. \& Bennell conducted the study on younger patients effected with cartilage lesions and extracted the same results from their studies as mentioned above. ${ }^{18,19}$

However, Filardo and his fellow colleagues used PRP and HA as treatment regime and found out that both are of equal importance in reducing OA symptom and severity with a significant $p$-value of $<0.0005$ and both drugs have shown similar trend for all clinical scores used. ${ }^{20}$

A study reported $50 \%$ decrease in VAS at 3 months in $15(55.5 \%)$ treated with PRP and $8(30.7 \%)$ patients treated with HA with insignificant difference, $p$-value $=0.227 .4 \mathrm{We}$ in current study also found that in PRP group there were $38(58.5 \%)$ cases in which $\geq 50 \%$ reduction in pain was seen while in $27(41.5 \%)$ cases the reduction of pain was $<50 \%$.

\section{Conclusion}

Through the findings of this study we conclude that the efficacy of efficacy of PRP was high than HA for treatment of Knee osteoarthritis. In future PRP can be utilized to reduce the symptom, pain and to improve better functions of knee.

\section{Conflict of Interest: None}

\section{References}

1. Wood AM, Brock TM, Heil K, Holmes R, Weusten A. A review on the management of hip and knee osteoarthritis. Int j chron disease 2013; 2013(1):1-10.

2. Zhang Y, Jordan JM. Epidemiology of Osteoarthritis. Clinic Geriatric Med 2010;26(3):355-69.

3. Hoorntje A, Witjes S, Koenraadt KL, Aarts R, de
Weert T, van Geenen RC. More severe preoperative Kellgren-Lawrence grades of knee osteoarthritis were partially associated with better postoperative patient-reported outcomes in TKA patients. J knee surg. 2019 Mar; 32(03):211-7.

4. Montañez-Heredia E, Irízar S, Huertas PJ, Otero E, del Valle M, Prat I, et al. Intra-articular injections of platelet-rich plasma versus hyaluronic acid in the treatment of osteoarthritic knee pain: a randomized clinical trial in the context of the Spanish National Health Care System. Int J Molecul Sci 2016; 17(7): 1064-76.

5. Seleem N, Elshereef E, Elhosary A, Salama N. Intraarticular injections of platelet-rich plasma combined with hyaluronic acid versus hyaluronic acid alone in treatment of knee osteoarthritis. Europ J Pharm Med Res 2017;4(4):608-15.

6. Mlynarek RA, Kuhn AW, Bedi A. Platelet-rich plasma (PRP) in orthopedic sports medicine. Am J Orthop. 2016 May; 45(5):290-326.

7. Hussain N, Johal H, Bhandari M. An evidence-based evaluation on the use of platelet rich plasma in orthopedics-a review of the literature. Sicot-j. 2017;3 (57).1-7.

8. Duymus TM, Mutlu S, Dernek B, Komur B, Aydogmus S, Kesiktas FN. Choice of intraarticular injection in treatment of knee osteoarthritis: platelet-rich plasma, hyaluronic acid or ozone options. Knee Surg, Sports Traumatol, Arthroscop 2016:doi: 10.1007/ s00167-016-4110-5.

9. Lopes de Jesus CC, dos Santos FC, de Jesus LM, Monteiro I, Sant' Ana MS, Trevisani VF. Comparison between intra-articular ozone and placebo in the treatment of knee osteoarthritis: A randomized, double-blinded, placebo-controlled study. PloS one. 2017 Jul ;12(7):e0179185.

10. Smith PA. Intra-articular autologous conditioned plasma injections provide safe and efficacious treatment for knee osteoarthritis: an FDA-sanctioned, randomized, double-blind, placebo-controlled clinical trial. Am j sports med. 2016 Apr; 44(4):884-91.

11. Shen L, Yuan T, Chen S, Xie X, Zhang C. The temporal effect of platelet-rich plasma on pain and physical function in the treatment of knee osteoarthritis: systematic review and meta-analysis of randomized controlled trials. J Orthop Surg Res 2017;12(1):16.

12. Navani A, Li G, Chrystal J. Platelet Rich Plasma in Musculoskeletal Pathology: A Necessary Rescue or a Lost Cause? Pain physician 2017;20(3):345-56.

13. Iqbal MN, Haidri FR, Motiani B, Mannan A. Frequency of factors associated with knee osteoarthritis. J Pak Med Assoc. 2011 Aug; 61(8):786-2. 
14. Meheux CJ, McCulloch PC, Lintner DM, Varner KE, Harris JD. Efficacy of Intra-articular Platelet-Rich Plasma Injections in Knee Osteoarthritis: A Systematic Review. Arthroscopy 2016;32(3):495-505.

15. Khoshbin A, Leroux T, Wasserstein D, Marks P, Theodoropoulos J, Ogilvie-Harris D, et al. The efficacy of platelet-rich plasma in the treatment of symptomatic knee osteoarthritis: a systematic review with quantitative synthesis. Arthroscopy 2013; 29(12): 2037-48.

16. Chang KV, Hung CY, Aliwarga F, Wang TG, Han DS, Chen WS. Comparative effectiveness of platelet-rich plasma injections for treating knee joint cartilage degenerative pathology: a systematic review and meta-analysis. Arch Phys Med Rehabil 2014; 95(3): 562-75.

17. Simental-Mendía M, Vílchez-Cavazos JF, PeñaMartínez VM, Said-Fernández S, Lara-Arias J, Martínez-Rodríguez HG. Leukocyte-poor plateletrich plasma is more effective than the conventional therapy with acetaminophen for the treatment of early knee osteoarthritis. Arch orthop traum su. 2016 Dec; 136(12):1723-32.
18. Kon E, Mandelbaum B, Buda R, Filardo G, Delcogliano M, Timoncini A, et al. Platelet-rich plasma intra-articular injection versus hyaluronic acid viscosupplementation as treatments for cartilage pathology: from early degeneration to osteoarthritis. Arthroscopy 2011;27(11):1490-501.

19. Bennell KL, Hunter DJ, Paterson KL. Platelet-rich plasma for the management of hip and knee osteoarthritis. Curr rheumatol rep. 2017 May; 19(5): 24.

20. Filardo.... Di Martino A, Di Matteo B, Papio T, Tentoni F, Selleri F, Cenacchi A, Kon E, Filardo G. Platelet-rich plasma versus hyaluronic acid injections for the treatment of knee osteoarthritis: results at 5 years of a double-blind, randomized controlled trial. Am j sports med.2019 Feb;47 (2):347-54.

\section{Authors Contribution}

AM: Concept, Data Analysis

AMM: Discussion Writing

ZM: Initial Drafting

SF, SA: Data Collection

MF: References writing and final proof reading 